DOI https://doi.org/10.30525/978-9934-26-073-5-2-43

\title{
PODCASTING AS A NEW MEDIA FORMAT OF PUBLIC COMMUNICATION IN THE DIGITAL AGE
}

\author{
Nypadymka A. S. \\ PhD in Humanitarian Sciences, \\ Associate Professor at the Department of Modern European Languages \\ Kyiv National University of Trade and Economics
}

Hudym A. D. $2^{\text {nd }}$ year student, Faculty of Trade and Marketing Kyiv National University of Trade and Economics Kyiv, Ukraine

In the era of graphic interfaces most of the data is displayed on screens of computers but media outlets have been experimenting with innovative formats. The biggest challenge facing everyone in the media industry today is the changing ways people consume content. All of them see podcasting as an additional opportunity to interact with their audiences. The prevalence and growing popularity of alternative content based on listening is going to make a difference in media market. And 2020 was a huge year for podcasting. Forecasts for the US suggest that the number of podcast listeners will surpass 160 million in 2023 after increases of around 20 million each year [6].

The word «podcasting» comes from combining the word iPod with broadcasting [2, p. 32]. The Cambridge Dictionary defines podcasting as the process of making digital recordings of radio programmes that people can download from the Internet [1]. Bringing news and content into audio format has direct impact on perception of information by listeners. When you listen to the speaker it is easier to determine whether a person is trustworthy and confident in informative speeches and a reliable source of information. It is an empirically proven fact that it is easier to believe, feel sympathy and «resonate» with another person, when we listen to his voice. This effect works in media as well. A person's manner of speaking is called prosody. It helps us make the message understandable, show our intentions and convey feelings. Moreover, prosody heightens the listener's attention and enhances their understanding. It is linked to the emotional parts of the brain and therefore when we hear a voice we have a sensation of being accompanied. It creates a strong emotional bond and causes a pleasant sensation of wellbeing [4, p. 80]. According to Rodero (2018) «all in all, the advantage of digital orality lies in 164 
the ability to access content where a human being tells a story, informs, helps, advises or interacts with us using all the prosodic aspects of their voice» [4, p. 80].

Being around other people provides safety and security that stifles this stress and decreases the feeling of loneliness. Audio content can be a powerful tool in fighting early stages of loneliness and prevent it from turning into a severe mental health issue. Hearing human voices has calming effect and makes a person imagine himself as a participant of a conversation. We could assume that it is the main reason why in October 2020, it was found that the most popular podcast genre in the United States was comedy, with 22 percent of respondents to a survey stating that they were very interested in podcasts designed to make them laugh [5].

Also in Casares and Binkley (2020) study the role of podcasts in bibliotherapy. Podcasts are set to be integrated into the clinical practice, a modernized version of bibliotherapy, which generally refers to the use of literature to help people cope with emotional problems, mental illness, or changes in their lives. Nowadays therapists can use specific merits of audio content to address a diverse range of client issues and facilitate the process of growth, healing, and change [3, p. 19].

Textual or computerized communications although framed as «conversations,» is deprived of rich subtext, emotional warmth. It is also supposed that implementing the ability to communicate via voice in social media helps people feel closer to each other and less lonely. The demand for such communication has resulted in the rocketing number of downloads of voicebased social media in the beginning of 2021. The best example to illustrate such a tendency is the Clubhouse application. Created primarily for audio chats, it had an increasing number of downloads in January 2021, with approximately two million users worldwide [7].

The situation in Ukraine is completely different, with less listening statistics and the podcast market while relatively small. Although, the PodcastsNOWua.com community has been established in the country, podcasting in Ukraine remains far from mainstream. Radio Podil has been promoting podcasts for a year. The first episode of Podcast Pidkast was released in March 2019. Ukrayinska Pravda has been developing and promoting podcasts since 2019 , and during this time many podcasts became popular: «Kliati Pytannia», «Temperatura - Normalna!», «Do Popkornu z Annoiu Palenchuk», «Rankova Doza», «Ukraina Pislia Karantynu», «Kultura Vseho», «Ok i Sho?», «Ya ne Vstyhaiu», «Akustyka Tinei». But Ukraine has seen a good increase in weekly podcast listening each year. Media outlets in Ukraine are increasingly turning to the podcasting format and have been 
actively engaged in podcast production. More and more radio stations (Radio Skovoroda, Urban Space Radio, Radio Aristocrats, Radio NV) are creating their podcasts and reaching their target audience.

In order to practically establish popularity of podcasts, we conducted students' needs analysis at different departments of Kyiv National University of Trade and Economics. The analysis was held in form of a questionnaire proposed to students during the second semester of the academic year 2020-2021.

263 students from the first to the second year of study participated in the anonymous questionnaire. The respondents were asked to answer 2 questions of the questionnaire covering the frequency of listening to podcasts and types of activities while listening. The results of the questionnaire are presented and discussed below.

A good number of students admitted they listen to podcasts $(77,5 \%)$. Dealing with the question about the frequency of listening to podcasts, most respondents listen to podcasts once every two weeks $(27,5 \%) ; 16,7 \%$ of students listen to podcasts one time a week and $18,3 \%$ of students listen to podcasts two or three times a week. Students seemed to be least enthusiastic about listening to podcasts three or four times a week (12,5\%), only $2,5 \%$ of students listen to podcasts daily and $22,5 \%$ of respondents do not listen to podcasts at all.

As the world becomes busier, the podcast format has become incredibly popular. Podcast audio content allows the listener to multitask. The biggest part of respondents answered that podcast listening happens while doing different activities $(72,4 \%)$ : while exercising $(4,2 \%)$, while travelling on public transport $(15,3 \%)$, while drawing or doing another art/hobby $(15,3 \%)$, a slightly bigger number of students $(18,8 \%)$ answered that podcast listening happens while cooking, and $18,8 \%$ of the respondents answered that podcast listening happens while cleaning. $27,6 \%$ of responders answered that podcast listening happens while they doing nothing.

It should be noted that human voice is a powerful tool, and it deserves a bigger role in our lives. The words, how the presenters communicate their message and their tone of voice are key elements for reliability and credibility between the presenters and audience. Most of respondents (74,3\%) answered that the timbre of the presenter's voice can influence their choice of podcast. For $25,7 \%$ of respondents the timbre of the presenter's voice does not play an important role in their choice of podcast.

Hopefully, we'll see lots of new audio-oriented media and up-to-date technology all humanity benefits from. And now when our digital platforms are finally sophisticated enough, voice could soon emerge as one of the most 
important content. The signal is clear: the pandemic provided a new impetus for podcasts around the world. Podcasts in Ukraine while relatively small, are poised to grow and outgrowing their «niche» status to emerge as substantive markets in their own right.

\section{References:}

1. Cambridge Dictionary. Retrieved on March 14, 2021 from: https://dictionary.cambridge.org/dictionary/english/podcast

2. Campbell G., «There's something in the Air: Podcasting in Education,» Educause review, vol. 40, no.6, November/December 2005. Retrieved on March 16, 2021 from https://er.educause.edu/articles/2005/1/theressomething-in-the-air-podcasting-in-education

3. Casares R. Jr., D. \& Binkley E. (2020). Podcasts as an Evolution of Bibliotherapy. Jounal of Mental Health Counseling. 43. P.19-39. Retrieved on March 3, 2021 from https://www.researchgate.net/publication/343920973_ Podcasts_as_an_Evolution_of_Bibliotherapy

4. Rodero E. (2018). The growing importance of the voice and sound in communication in the digital age: the leading role of orality. AC/E Digital Culture Annual Report 2018. Digital Trends in Culture. P. 78-87. Retrieved on March 13, 2021 from https://www.researchgate.net/publication/326692 799_THE_GROWING_IMPORTANCE_OF_THE_VOICE_AND_SOUND_ IN_COMMUNICATION_IN_THE_DIGITAL_AGE_THE_LEADING_ROL E_OF_ORALITY

5. Statista Research Department. Leading podcast genres in the United States in October 2020. 08.01.2021. Retrieved on March 3, 2021 from https://www.statista.com/statistics/786938/top-podcast-genres/

6. Statista Research Department. Number of monthly podcast listeners in the United States from 2014 to 2023. Retrieved on March 3, 2021 from https://www.statista.com/statistics/786826/podcast-listeners-in-the-us

7. Statista Research Department. Number of weekly active Clubhouse users from April 2020 to January 2021. 24.02.2021. Retrieved on March 3, 2021 from https://www.statista.com/statistics/1199871/number-of-clubhouseusers/ 